\title{
Effects of Background Illumination on the Horizontal Cell Responses in the Tiger Salamander Retina
}

\author{
Xiong-Li Yang and Samuel M. Wu \\ Cullen Eye Institute, Baylor College of Medicine, Houston, Texas 77030
}

\begin{abstract}
Synaptic transmission between photoreceptors and horizontal cells (HCs) was studied in the flat-mounted isolated retinas of the tiger salamander. Background illumination expedited the rise time of the $\mathrm{HC}$ light response, and the $\mathrm{HC}$ response rise time (HCRRT) reached steady state about 2 sec after the onset of the background illumination. The change in HCRRT is probably responsible for the background-induced enhancement of the $\mathrm{HC}$ responses to short light stimuli. The amplitude of the $\mathrm{HC}$ responses to $100 \mathrm{msec}$ light steps in the presence of background illumination was 2-5 times larger than that measured under dark-adapted conditions. Background illumination exerted little effect on the response rise time in cones and bipolar cells, and thus it caused no significant response enhancement in those cells. The background-induced change in HCRRT correlated closely with the rod voltage but not with the HC voltage. These results suggest that the background-induced change in HCRRT is probably mediated by postsynaptic events in $\mathrm{HCs}$ because no significant time course change is observed in photoreceptors and bipolar cells (which share the same synapses with the HCs). A suppressive rod action on the cone inputs in HCs may be responsible for modulating the HCRRT. By shortening the HCRRT, background illumination regulates the frequency response of the photoreceptor-HC synapse and alters the capacity of spatial resolution of retinal bipolar cells.
\end{abstract}

In the vertebrate retina, photoreceptors continuously release neurotransmitters in darkness, which depolarizes the horizontal cells (HCs) (Byzov and Trifonov, 1968; Dowling and Ripps, 1973; Schacher et al., 1974). Light hyperpolarizes the photoreceptors and reduces neurotransmitter release, which results in a hyperpolarizing response in HCs (Dowling and Ripps, 1973; Dacheux and Miller, 1976). It is possible that the efficacy or gain of the photoreceptor-HC synapse is modulatable by light or darkness. In Xenopus, mudpuppy, and fish retinas, background illumination increased the amplitude of the $\mathrm{HC}$ responses to light steps and flickers (Hassin and Witkovsky, 1983; Frumkes and Eysteinsson, 1987; Yang et al., 1988a). It is not clear, however, whether these changes in $\mathrm{HC}$ responses are me-

\footnotetext{
Received Mar. 28, 1988; revised Aug. 5, 1988; accepted Aug. 12, 1988.

We thank Professors John E. Dowling and Daniel Johnston for reading the manuscript and providing many helpful comments. This work was supported by grants from the National Institutes of Health (EY 04446) and from the Retinal Research Foundation (Houston). X.-L.Y. was a Foreign Fellow of the Research to Prevent Blindness, Inc.

Correspondence should be addressed to Samuel $\mathrm{M}$. Wu, Cullen Eye Institute Baylor College of Medicine, One Baylor Plaza, Houston, TX 77030.

Copyright $\odot 1989$ Society for Neuroscience $0270-6474 / 89 / 030815-13 \$ 02.00 / 0$
}

diated by modification of the presynaptic light responses in the photoreceptors or by changes in efficacy of the photoreceptor$\mathrm{HC}$ synapse. In addition to changing the response amplitude, background light also alters the time course and waveform of the $\mathrm{HC}$ responses: the rise of the $\mathrm{HC}$ responses under lightadapted condition is much faster than that in darkness, and an off-overshoot response can be observed in light-adapted HCs but not in dark-adapted HCs (Tauchi et al., 1984; Wu, 1987a, b). These light-dependent changes in response kinetics may affect the modulation of response amplitude in the following ways: (1) For short light stimuli, the amplitude of the $\mathrm{HC}$ response is larger if the rise time course is faster and (2) the amplitude of the $\mathrm{HC}$ responses to repctitive light flashes (flickers) is progressively larger when a depolarizing overshoot is present after each flash, i.e., the $\mathrm{HC}$ baseline is progressively depolarized by the repetitive overshoot responses (Wu, 1988).

The purpose of this study is to characterize the mechanisms underlying the light-dependent modulation of the rise time course of the $\mathrm{HC}$ response, and its relationship with the backgroundinduced changes in the $\mathrm{HC}$ response amplitude. Since the time to peak of the $\mathrm{HC}$ response under dark-adapted condition is about 1-2 sec and the response kinetics during this period of light exposure may change significantly, it is therefore difficult to determine accurately the response kinetics by measuring the time to peak of the $\mathrm{HC}$ responses. In this study, the standard stimuli we used are short light steps (100 msec), during which the response kinetics do not change significantly. The interstimuli duration is set to be $5-10 \mathrm{sec}$ so that $\mathrm{HC}$ off-overshoot responses under light-adapted conditions can have sufficient time to relax back to the baseline level before the next stimulus is turned on.

\section{Materials and Methods}

The preparations. Larval tiger salamander (Ambystoma tigrinum) purchased from the Lowrance Waterdog Farm (Tulsa, OK) were used in this study. Prior to an experiment, the animal was dark-adapted overnight and then decapitated under infrared illumination. The eyes were enucleated and hemisected. A piece of the posterior half of the eyecup was inverted over a piece of Millipore filter paper (HAO $0.45 \mu \mathrm{m}$ ) secured in the superfusion chamber. The sclera and the pigment epithelium were removed from the retina. Oxygenated Ringer's solution was added to the superfusion chamber so that the retina was immersed totally under solution. Flat-mounted isolated retinas and living retinal sliccs were used in this study, and the detailed description of these preparations were given in Werblin (1978) and Wu (1987c). The entire procedures were done under infrared illumination with a dual unit fineR-scope (FJW Industry, Mount Prospect, IL). The retinal cells were viewed by a $40 \times$ Zeiss water immersion objective lens modified for the Hoffman modulation contrast optics (Hoffman Modulation Optics, Greenvale, NY). During the experiment, retinal cells as well as the 2 electrodes were clearly observed on the screen of a TV monitor con- 
$\mathbf{A}$

Figure 1. Voltage response of a $\mathrm{HC}$ to long $(4 \mathrm{sec})$ and short $(100 \mathrm{msec})$ light steps (lower traces) under dark-adapted condition $(A)$ and in the presence of $(500$ $\mathrm{nm} /-3.12$ background illumination $(B)$. All test light steps used in this figure were of the same intensity and wavelength $(700 \mathrm{~nm} /-0.33)$. The resting potential of the $\mathrm{HC}$ under dark-adapted condition $(A)$ was about $-20 \mathrm{mV}$.
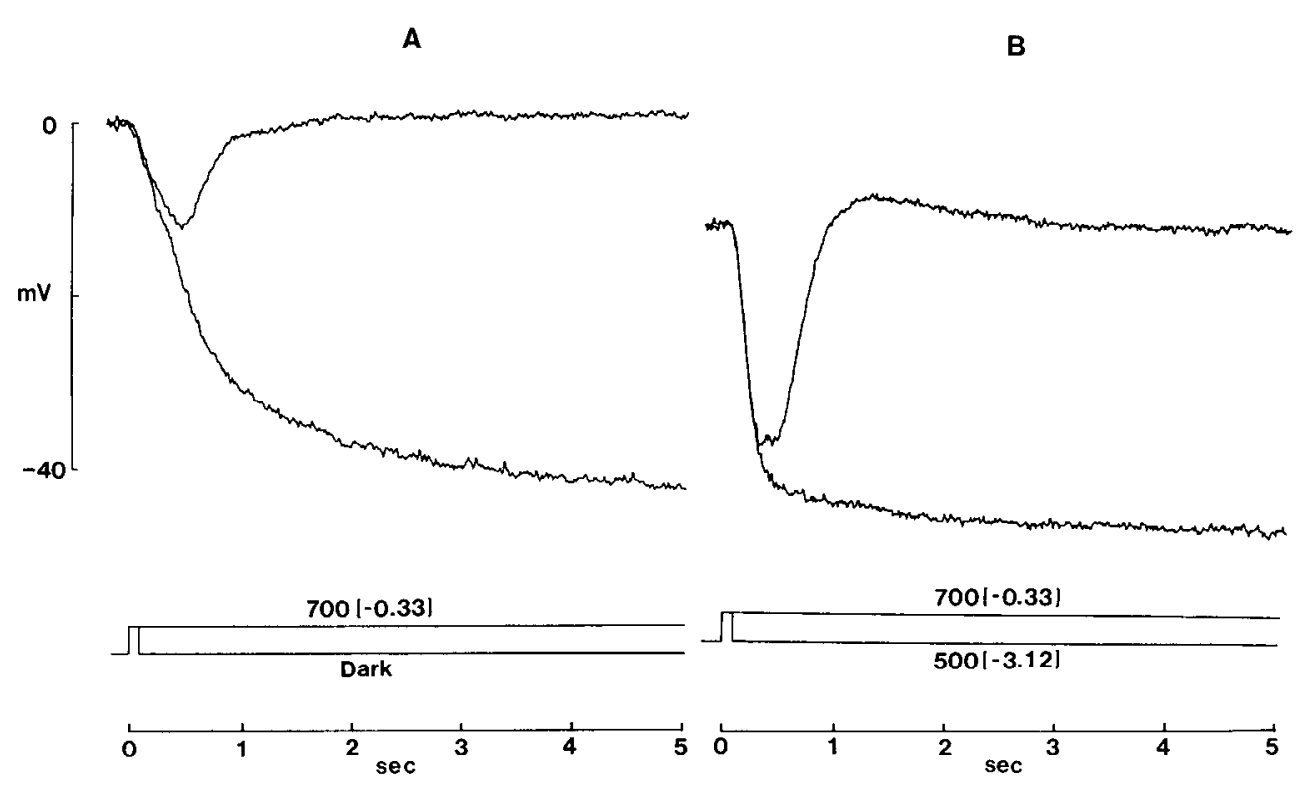

nected to the infrared image converter (COHU, Palo Alto, CA, model 4415) attached to the microscope.

Recording and stimulation. Intracellular recording and current injection were made with micropipettes drawn out on a modified Livingston puller with omega dot tubing ( $1.0 \mathrm{~mm}$ OD and $0.5 \mathrm{~mm}$ ID). The micropipettes were filled with 2 м potassium acetate, and had tip resistances, measured in Ringer's solution, of 100-600 M $\Omega$.

The membrane potential of photoreceptors was recorded as the potential difference between the intracellular recording electrode and the bath electrode. Two intracellular electrodes were sometimes inserted into 2 retinal cells to monitor the simultaneous light responses.

Retinal cells were impaled under visual control, in either the flatmounted retinas or in the slices and the impalement was facilitated by adjusting the negative capacitance in the electrode headstage. Voltage and current traces were monitored with an oscilloscope (Tektronix 5500A) and stored in magnetic tapes (Racal 7DS).

Solutions. Preparations were maintained at room temperature (20$23^{\circ} \mathrm{C}$ ) in an oxygenated Ringer's containing $108 \mathrm{mM} \mathrm{NaCl}, 2.5 \mathrm{mM} \mathrm{KCl}$, $1.2 \mathrm{~mm} \mathrm{MgCl}_{2}, 2 \mathrm{~mm} \mathrm{CaCl}$ and $5 \mathrm{~mm}$ Hepes adjusted at $\mathrm{pH} 7.7$.

Light source. The preparation was stimulated with a dual-beam photostimulator. Two independent light beams whose intensity and wavelength could be adjusted by neutral density filters and interference filters were provided by quartz halogen sources. The light was transmitted to the preparation via the epi-illuminator and the objective lens of the microscope, and the spot diameter on the retina could be adjusted by a diaphragm in the epi-illuminator. In most experiments described in the article, large field illumination (600-1200 $\mu \mathrm{m}$ in diameter) was used. The light sources were calibrated with a radiometric detector (United Detector Technology, Inc.). The intensity of unattenuated $600 \mathrm{~nm}$ light is $9.42 \times 10^{17}$ photons $\mathrm{sec}^{-1} \mathrm{~cm}^{-2}$. All light stimuli used in this article are described by pairs of numbers (e.g., $500 \mathrm{~nm} /-1.32$ ), with the first number indicating the wavelength and the second number indicating the relative attention (in $\log$ units) with respect to the intensity of the $600 \mathrm{~nm}$ given above.

\section{Results}

Effects of background illumination on the time course and amplitude of the $\mathrm{HC}$ responses

Figure 1 shows the voltage responses of a $\mathrm{HC}$ to long $(4 \mathrm{sec})$ and short $(100 \mathrm{msec})$ light steps under dark-adapted condition $(A)$ and in the presence of background illumination $(B)$. Under dark-adapted conditions (Fig. $1 A$ ), the amplitude of the $\mathrm{HC}$ response to the long light step $(700 \mathrm{~nm},-0.33)$ was about 40 $\mathrm{mV}$ and the time to peak was about $4 \mathrm{sec}$. Because of its slow rise, the $\mathrm{HC}$ response to the short light step of the same intensity
$(700 \mathrm{~nm},-0.33)$ could only reach an amplitude of about 12 $\mathrm{mV}$. In the presence of background illumination (Fig. $1 B$ ), the $\mathrm{HC}$ was steadily hyperpolarized for about $10 \mathrm{mV}$, and the response to the long light step reached the peak voltage of approximately the same level as Figure $1 A$ but the time to peak was only about $1 \mathrm{sec}$. Because of this faster rise, the $\mathrm{HC}$ response to the short light step could reach an amplitude of about $26 \mathrm{mV}$ (increment response measured from the ambient voltage). This result demonstrates that the rising time course of the $\mathrm{HC}$ light responses in dark-adapted retina can be shortened by background illumination, and the amplitude of the $\mathrm{HC}$ responses to short $(100 \mathrm{msec})$ light steps is closely related with the response rise time. As it will be shown later in this paper, the backgroundinduced change of the $\mathrm{HC}$ response rise time (HCRRT) occurs about $200 \mathrm{msec}$ after the onset of background light. It is, therefore, inappropriate to use the time to peak of the $\mathrm{HC}$ responses to long light steps to characterize the rise time of the $\mathrm{HC}$ response at a given background level, because the long test light itself will induce changes of the response rise time. The amplitude of the $\mathrm{HC}$ responses to $100 \mathrm{msec}$ light steps, on the other hand, provides a good index in characterizing the rise time of $\mathrm{HC}$ responses for the following reasons: (1) Within a certain range of background intensity and test light intensity, the amplitude of the $\mathrm{HC}$. response to $100 \mathrm{msec}$ light steps is larger when the time to peak of the $\mathrm{HC}$ response is shorter; (2) the $100 \mathrm{msec}$ light step is short enough so that it does not induce significant changes in response time course; and (3) it is convenient. For most of the rest of the experiments described in this article, we used 100 msec light step as the standard test flash and the amplitude of the response to this test flash as an indicator of the response rise time: a larger response amplitude represents a faster rise time.

Figure $2 A$ shows the voltage responses of a dark-adapted $\mathrm{HC}$ to 100 msec light steps in the presence of background light of various intensities. In darkness, $100 \mathrm{msec}$ flashes elicited small $\mathrm{HC}$ responses. In the presence of background illumination, the amplitude of the responses (increment responses measured from the ambient potential levels) to the same test flashes increased progressively with the background intensity. Figure $2 B$ shows 

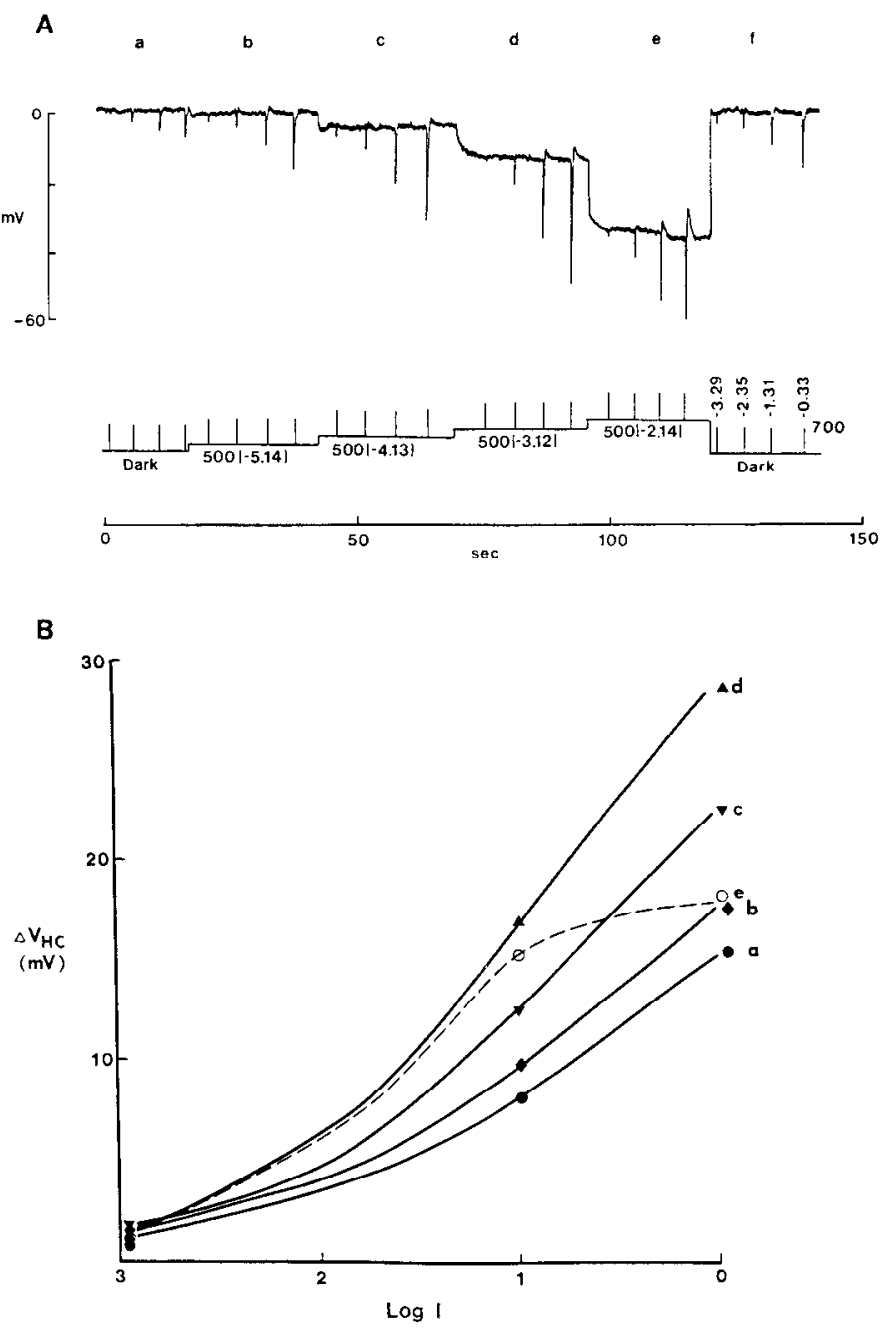

Figure 2. A, Voltage responses of a dark-adapted $\mathrm{HC}$ to $100 \mathrm{msec}$ light steps (upright bars in lower trace) of various intensities $(700 \mathrm{~nm} /-3.29$, $700 \mathrm{~nm} / 2.35,700 \mathrm{~nm} /-1.31,700 \mathrm{~nm} /-0.33)$ in the presence of background illumination of various intensities (steps in lower trace: a, dark; $b, 500 \mathrm{~nm} /-5.14 ; c, 500 \mathrm{~nm} /-4.13 ; d, 500 \mathrm{~nm} /-3.12 ; e, 500 \mathrm{~nm} /$ $-2.14 ; f$, dark). The dark resting potential of the HC was about -19 $\mathrm{mV} . B$, Voltage-intensity $(V-\log I)$ relations of the increment responses (measured as the response amplitude from the ambient levels) of the HC shown in $A(a-c$ same as in $A)$.

the voltagc-intensity $(V-\log I)$ relations of the increment responses of the HC shown in Figure $2 A$. In the presence of dim and intermediate background illuminations $(a-d)$, the response amplitude increased with the intensity of the background light, indicating that the rise time of the $\mathrm{HC}$ response became progressively faster as brighter background light was delivered to the retina. In the presence of bright background light $(e)$, the increment responses to bright test flashes $(-1.31$ and -0.33$)$ became smaller (dashed line in Fig. $2 B$ ), although the absolute levels of hyperpolarization of these responses (resultant responses $=$ background response + increment response) were lower than those in $d$. This saturation of the $\mathrm{HC}$ increment responses is due to the fact that the sum of the background and test lights $(-1.31$ and -0.33$)$ in $e$ is bright enough to hyperpolarize the $\mathrm{HC}$ to the peak voltage $(-80 \mathrm{mV})$. The results shown in Figure 2 suggest that the dynamic range of the back-
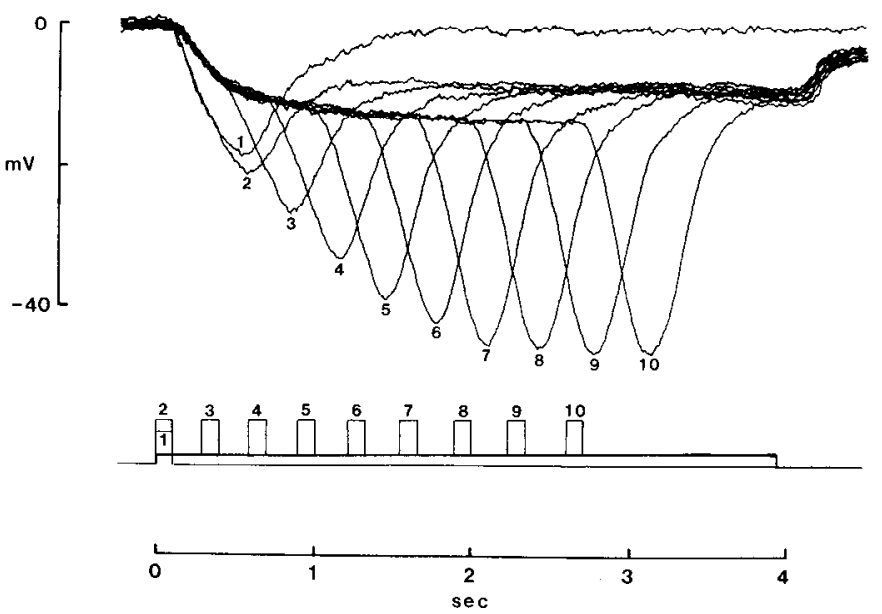

Figure 3. $\mathrm{HC}$ responses to $100 \mathrm{msec}$ test light steps $(700 \mathrm{~nm},-1.31)$ at various instances after the onset of steady background illumination $(500 \mathrm{~nm},-4.13)$. Ten traces of the $\mathrm{HC}$ responses to 10 identical test light steps are superimposed. The $\mathrm{HC}$ was dark-adapted initially with a resting potential about $-20 \mathrm{mV}$.

ground-induced changes of the HCRRT resides between 0 (darkness) and $-3 \log$ units $(500 \mathrm{~nm})$ of the background illumination.

\section{Kinetics of the background-induced change of the HCRRT}

The results described above have shown that steady background illumination expedites the rise time of the $\mathrm{HC}$ response. To study the mechanisms underlying this background-induced effect, it is important to detcrmine the timc coursc of the change of the HCRRT. Figure 3 shows the $\mathrm{HC}$ responses to $100 \mathrm{msec}$ test light steps at various instances after the onset of a steady background light. Test step 1 was given without background illumination, the onset of step 2 was given at the same time as the onset of the background light, and the onset of step 3 to 10 were given $0.3,0.6,0.9,1.2,1.5,1.8,2.1,2.4 \mathrm{sec}$ after the onset of the background light, respectively. The response to step 2 was slightly larger than that to step 1 because the background light added more intensity to the test light step. As the background light preceded the test step for longer periods (steps 310), the response amplitude became progressively larger because the rise time became faster. The response amplitude (and thus the rise time) reached a steady state when the background preceded the test step for approximately $2 \mathrm{sec}$. Figure 4 shows the time course of the background-induced change of the HCRRT. The amplitude of the resultant response to the 100 msec test step was plotted as a function of the time delay between the onset of the background and the onset of the test light step (Fig. 4A). Background lights of 2 intensities were used in this experiment and the time courses were plotted in semilog scales in Figure $4 B$. The changes of responses amplitude (and thus the response rise time) induced by the 2 backgrounds followed approximately the same exponential time course. The time to reach steady state was about 2 seconds.

\section{Cellular sites where background-induced changes of HCRRT may occur}

We have shown in the previous sections that the rise time of the $\mathrm{HC}$ responses, represented by the amplitude of the responses to $100 \mathrm{msec}$ light steps, becomes faster in the presence of background illumination. This background-induced change in $\mathrm{HC}$ 
A

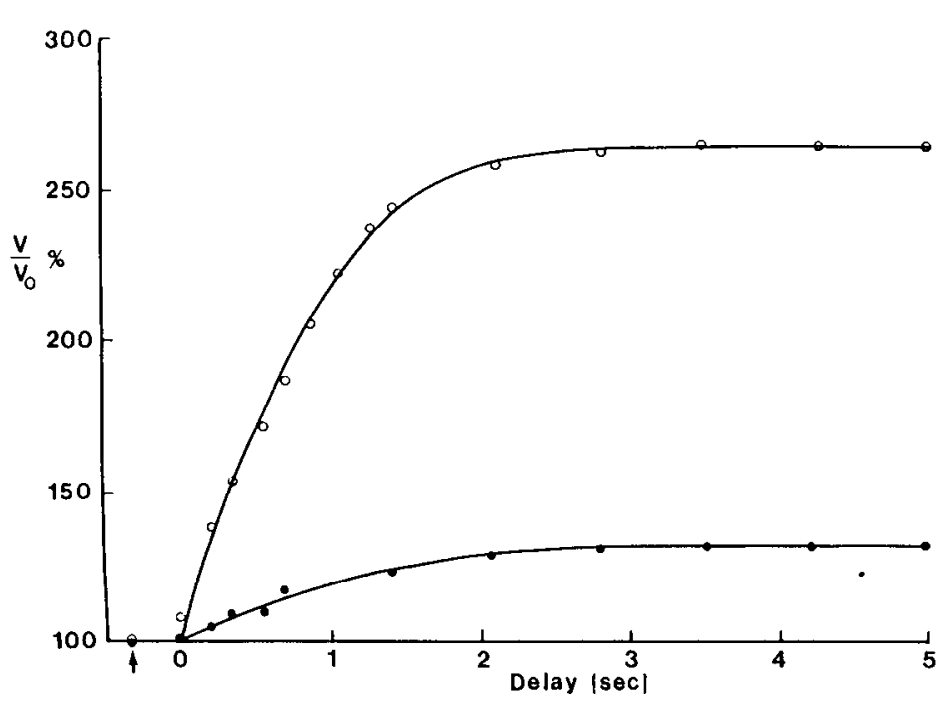

B

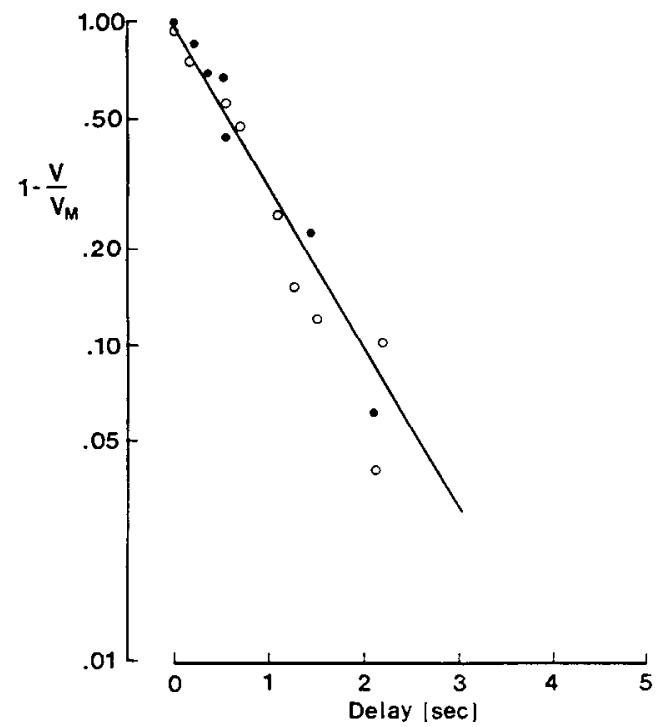

Figure 4. Time course of the background-induced change of the HCRRT. $V$ is the amplitude of the HC responses to $100 \mathrm{msec}$ test lights (700 $\mathrm{nm},-1.31)$ at various times after the onset of background illumination $\left(500 \mathrm{~nm},-4.13\right.$ : filled circles; $500 \mathrm{~nm},-3.12$ : open circles). $V_{\mathrm{o}}$ is the amplitude of the $\mathrm{HC}$ response to the same test light without background illumination. $V / V_{\mathrm{o}}$ is plotted against the delay (time between the onsets of the background light and the test light) in $A .1-V / V_{M}$ is plotted in a semilog scale against the delay in $B$, where $V_{M}$ is the maximum amplitude of the HC responses in the presence of the background illumination. This plot shows that the changes of HCRRT induced by the 2 backgrounds follow the same time course with a time-to-peak of about 2 sec.

responses may originate from several cellular sites in the retina.

1. Photoreceptors: Because HC light responses are mediated by the light responses of rods and cones in this retina (Hanani and Vallerga, 1980), changes in photoreceptor responses may alter the $\mathrm{HC}$ responses.

2. Photoreceptor terminals: Background illumination may alter the properties of the photoreceptor terminals which may be electronically insulated from the cell bodies where recordings are made.

3. Synaptic cleft: Background illumination may affect events occurring in the synaptic cleft such as the removal and uptake of the photoreceptor transmitters.

4. Postsynaptic membrane in HCs: Background illumination may alter the properties of the postsynaptic receptors and/or other proteins in the $\mathrm{HC}$ membrane.

To determine at which of the above sites background-induced changes of IICRRT occur, the effects of the background illumination on the photoreceptors and bipolar cell responses were examined. Figure 5 shows voltage responses of a rod, a cone, a $\mathrm{HC}$, and a hyperpolarizing bipolar cell (HBC) to $100 \mathrm{msec}$ light steps in the absence and presence of background illumination. The HC increment responses, similar to those shown in Figure 2 , was enhanced by background light. The amplitude of the increment responses of the rod, the cone, and the $\mathrm{HBC}$, on the other hand, was reduced by the background light. This result indicates that the background-induced change in rise time, represented by the amplitude of the responses to short test flashes seen in $\mathrm{HC}$, is not present in photoreceptors or bipolar cells. This is not a surprising conclusion when we examine the rise time of the photoreceptor, $\mathrm{HC}$, and bipolar cell responses to longer test light steps. Figure 6 shows the voltage responses of a cone, a rod, a $\mathrm{HC}$, and a $\mathrm{HBC}$ under dark-adapted condition to a $1 \mathrm{sec}$ light step. The time to peak of the rod, the cone, and the $\mathrm{HBC}$ was 50-150 msec, whereas that of the $\mathrm{HC}$ was about $1.5 \mathrm{sec}$. The time to peak of $\operatorname{rod}_{c}-\mathrm{a}$ small population of rods strongly coupled with cones (Wu and Yang, 1988)-and that of the depolarizing bipolar cells (DBC; Fig. 15) was also about 100-150 msec under dark-adapted condition, a $100 \mathrm{msec}$ light step could evoke maximum responses in photoreceptors and bipolar cells but not in HCs. Background illumination shortened the time to peak of $\mathrm{HC}$ and thus enhanced the $\mathrm{HC}$ responses to $100 \mathrm{msec}$ flashes. The rise time of the photoreceptors and bipolar cells was not significantly expedited by background illumination [10-25 msec changes, compared with the 1-3 sec changes in HCs (see Fig. 15, and also Baylor and Hodgkin (1974) and $\mathrm{Wu}(1987 \mathrm{~b})]$ and thus the resultant responses to $100 \mathrm{msec}$ flashes reached the same level as the responses recorded in darkness (Fig. 5).

Results described above suggest that the background-induced changes in HCRRT is unlikely to be the result of changes of the presynaptic light responses in photoreceptors because the amplitude of the rod and cones increment responses to $100 \mathrm{msec}$ flashes decrease in response to background illumination. Moreover, hecause the background-induced changes of responses rise time is not observed in either the HBCs or DBCs (Fig. 5, 15), it is unlikely that the changes in HCs are mediated by events occurring in the photoreceptor terminals or in the synaptic cleft. This is because bipolar cells and HCs in the tiger salamander retina share the same synapses in the rod and cone terminals and their dendrites are adjacent to each other in the diad or triad regions (Lasansky, 1973, 1978). Changes in photoreceptor terminals or in the synaptic cleft should have been recorded in both the bipolar cells and the HCs.

Background-induced modulation of $H C$ responses depends on the rod, but not the $\mathrm{HC}$, voltage

Our results in the previous section have suggested, by eliminating other cellular sites, that the background-induced changes of the $\mathrm{HC}$ response time course probably occur in the $\mathrm{HC}$ mem- 

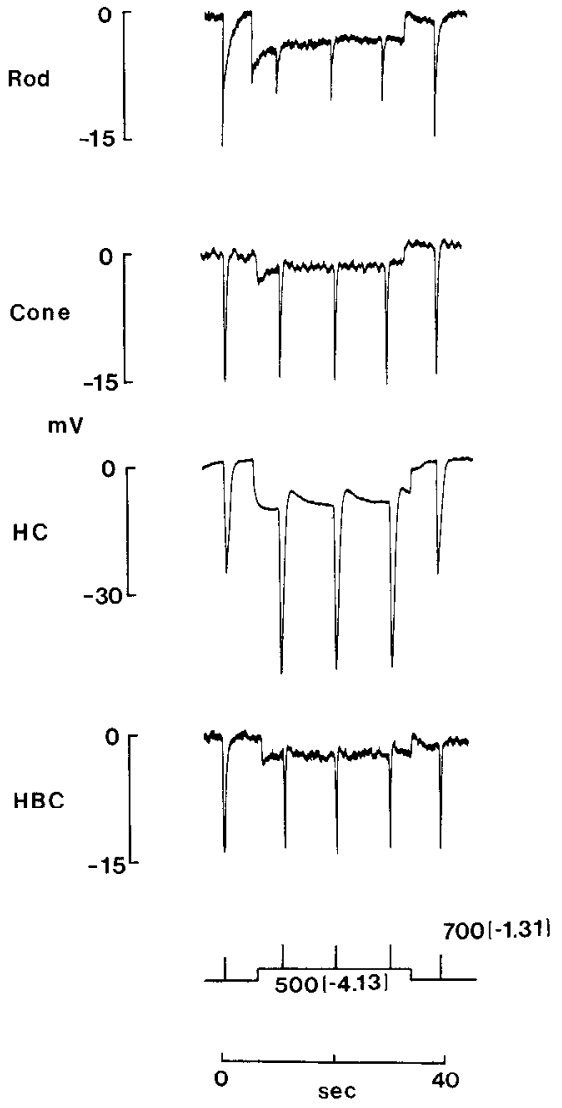

Figure 5. Voltage responses of a rod, a cone, a $\mathrm{HC}$, and a $\mathrm{HBC}$ to 100 msec light steps (upright bars in lower trace: $700 \mathrm{~nm},-1.31$ ) in the absence and presence of background illumination $(500 \mathrm{~nm},-4.13)$. The resting potentials of the rod, the conc, the HC, and the HBC werc -40 , $-41,-20$, and $-40 \mathrm{mV}$, respectively.

brane. Although $\mathrm{HC}$ light responses are mediated by the reduction of transmitter flow from photoreceptors, some voltagedependent currents in HC (c.g., Tachibana, 1983) may limit the rising rate of the $\mathrm{HC}$ light responses. Figure 7 shows the effect of depolarizing currents on the light responses of a $\mathrm{HC}$ in the presence of background illumination. The lowest trace $(I=0.0$ $\mathrm{nA}$ ) is the voltage response of a $\mathrm{HC}$ recorded in the presence of background illumination and the time to peak of this response is about $0.3 \mathrm{sec}$. Depolarizing current steps of various intensities (indicated by the numbers in $\mathrm{nA}$ on the left of each trace) was injected into the $\mathrm{HC}$ and the $\mathrm{HC}$ responses to the same test light in the presence of the same background light are shown in the upper traces. The amplitude of the responses became progressively larger for larger currents because the $\mathrm{HC}$ was depolarized further away from the peak light voltage. The slope of the rise of these responses, however, was approximately constant. This suggests that the $\mathrm{HC}$ response rise is probably independent of the $\mathrm{HC}$ voltage, and the background-induced modulation is probably not mediated by voltage-dependent currents in the HCs.

Figure 8 shows the effects of 500 and $700 \mathrm{~nm}$ background light on the $\mathrm{HC}$ responses to $100 \mathrm{msec}$ test flashes. Background light of $700 \mathrm{~nm} /-4.89,700 \mathrm{~nm} /-3.95,500 \mathrm{~nm} /-8.14$, and $500 \mathrm{~nm} /-7.14$ resulted in a steady hyperpolarization in the $\mathrm{HC}$ for $3.5,7,1$, and $3 \mathrm{mV}$, respectively (Fig. $8, A-D$ ). The degree of change of response rise time, as indicated by the ratio of the
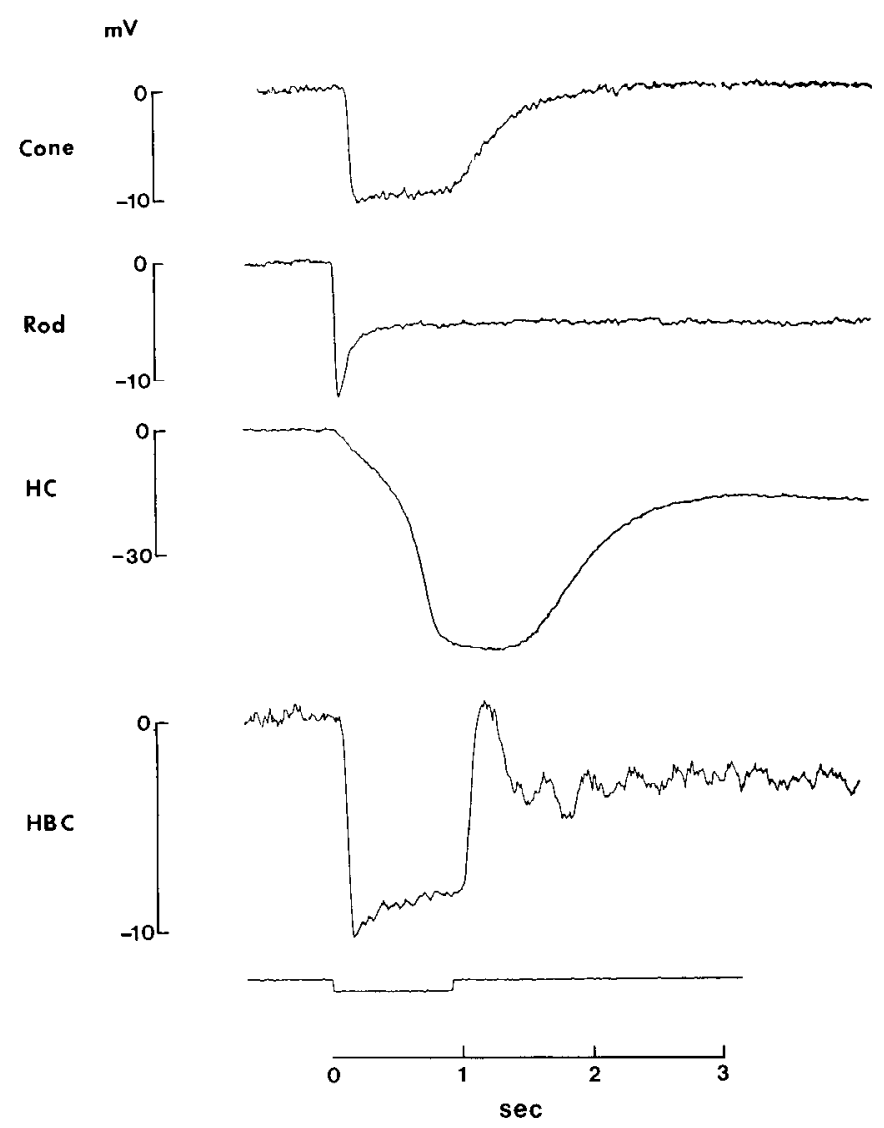

Figure 6. Voltage responses of a cone, a rod, a $\mathrm{HC}$, and a $\mathrm{HBC}$ under dark-adapted condition to a $1 \mathrm{sec}$ light $\operatorname{step}(520 \mathrm{~nm},-3.35)$. The timesto-peak of the 4 cells were about $100 \mathrm{msec}, 60 \mathrm{msec}, 1.5 \mathrm{sec}$, and 150 msce, respectivcly, and the resting potentials were $-38,-37,-17$, and $-40 \mathrm{mV}$, respectively.

resultant response (background response + increment response) to the dark response, was $1.27,1.48,1.30$, and 1.45 for Figure $8, A, B, C$, and $D$, respectively. It is clear from these data that the degree of change of $\mathrm{HC}$ response rise time does not correlate with the $\mathrm{HC}$ membrane potential, which is consistent with the conclusion drawn from the results shown in Figure 5; however, it correlates very well with the potential changes in rods. The $700 /-4.89$ and $500 /-8.14$ background lights (Fig. $8, A, C$ ) hyperpolarize the rods to approximately the same voltage, and so do the $700 /-3.95$ and $500 /-7.14$ background lights (Fig. 8, B, $D$ ) (Wu and Yang, 1988). The degree of rise time changes in Figure $8 A(1.27)$ is very close to that in $C(1.30)$, and that in $B$ $(1.48)$ is very close to that in $D(1.45)$. This correlation is further demonstrated in Figure 9, in which the sensitivity of the change of HCRRT is plotted against the wavelength of the background light. Data points (solid circles) were derived from the intensities of the background light required to elicit $\mathrm{HC}$ response of a given degree of change of HCRRT (represented by the ratio of the resultant response to dark response to $100 \mathrm{msec}$ flashes, see Fig. $8)$. The solid curves are the spectral sensitivities of the rod and the cone. The data points agree very well with the rod spectral sensitivity, suggesting that the background-induced modulation of the HCRRT is probably mediated by changes of the rod voltage.

To examine further the role of rods in modulating the $\mathrm{HC}$ response; we studied the effects of bleaching light on the back- 
$I(n A)$

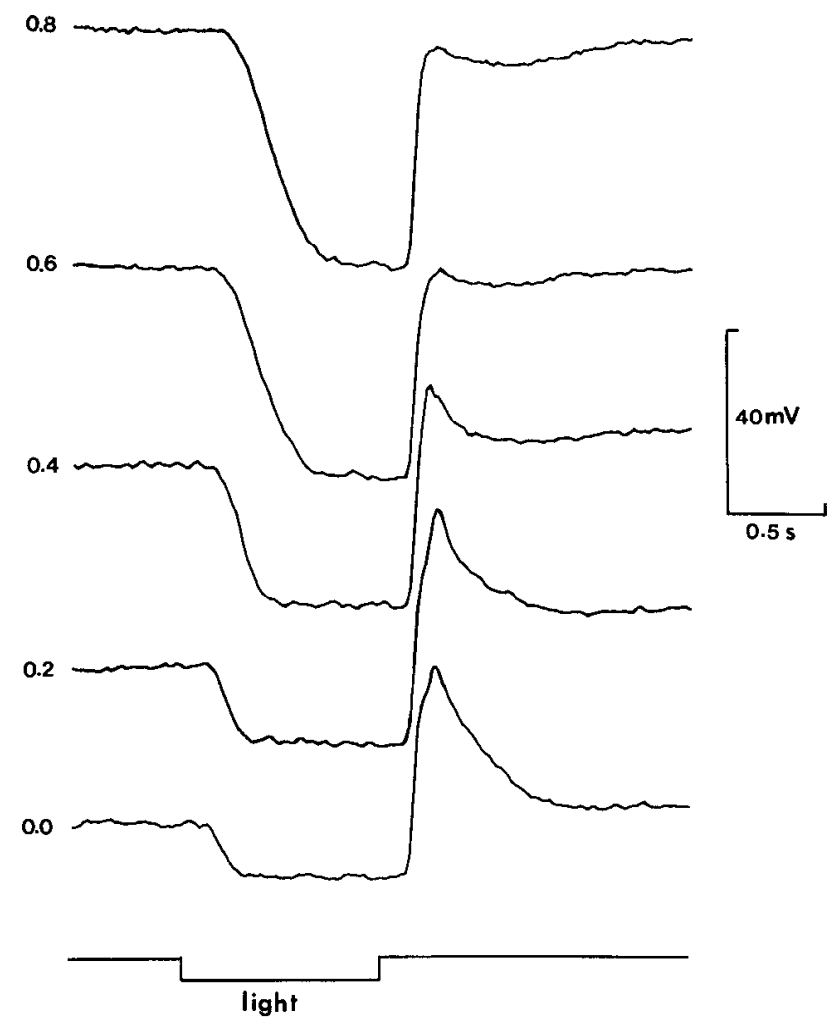

Figure 7. Effect of current injection on the $\mathrm{HC}$ responses to a $1 \mathrm{sec}$ light step $(520 \mathrm{~nm},-1.3)$ in the presence of background illumination $(500 \mathrm{~nm},-2.3)$. Current steps (values given at the left of each trace) were passed into the $\mathrm{HC}$ through the recording electrode and a bridge circuit. The same light step was delivered to the cell when it was depolarized by the current at various levels. The voltage scale indicates the voltage of each trace but not the intertrace spaces. The ambient potential of the $\mathrm{HC}$ without current $(0.0 \mathrm{nA})$ was about $-72 \mathrm{mV}$.

ground-induced change of the $\mathrm{HC}$ responses. Figure 10 shows the effects of background illumination on the $\mathrm{HC}$ responses to $100 \mathrm{msec}$ test flashes before and after bleaching. Under darkadapted condition (Fig. 10A), a $500 \mathrm{~nm} /-4.13$ background light caused a change in response rise time (represented by the ratio of resultant response to dark response) of 2.2. About $3 \mathrm{~min}$ after bleaching (Fig. 10C), when rods were still irresponsive to light (Wu, 1987b), the same background light caused no change in the response rise time (or enhancement of the $\mathrm{HC}$ response to $100 \mathrm{msec}$ flashes). This result is again consistent with the notion that the background-induced modulation of the $\mathrm{HC}$ response rise time is mediated by changes of the rod voltage.

\section{Background illumination primarily modulates postsynaptic receptors of cone transmitters in the $\mathrm{HC}$ membrane}

Results described so far have suggested that the backgroundinduced modulation of HCRRT is probably mediated by voltage-independent mechanisms in the $\mathrm{HC}$ membrane, and the modulation depends closely on the rod voltage. Since the $\mathrm{HC}$ light response results from the reduction of photoreceptor transmitters, it is reasonable to postulate that the rise of the $\mathrm{HC}$ light response is mediated by the dissociation of the photoreceptor transmitters and the postsynaptic receptors. In the tiger salamander retina, $\mathrm{HCs}$ receive inputs from both rods and cones
A
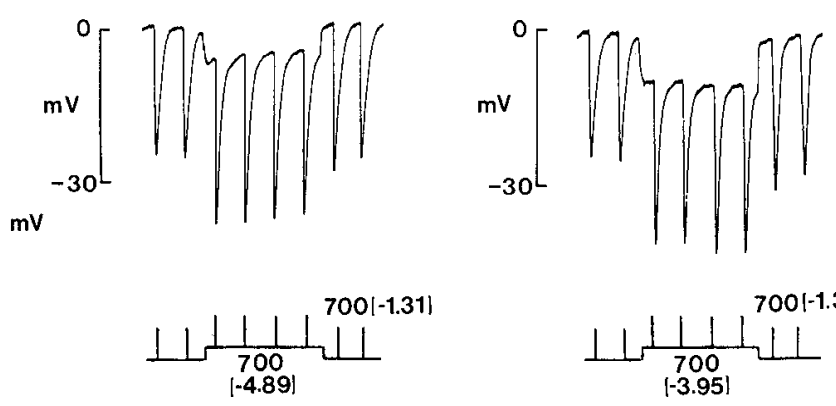

C
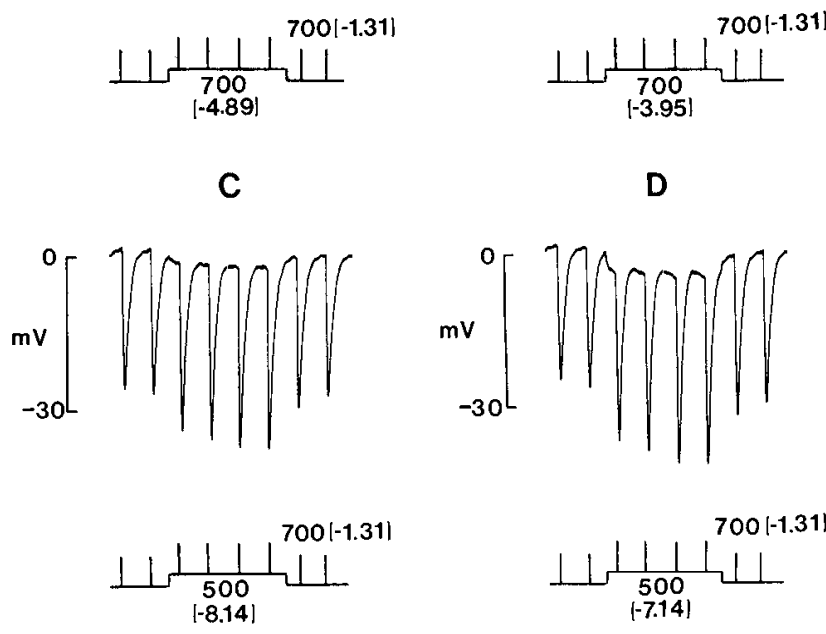

D

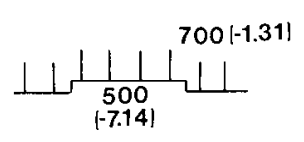

$\frac{1}{0 \quad \sec } \quad 80$

Figure 8. Effects of 500 and $700 \mathrm{~nm}$ background illumination on the $\mathrm{HC}$ responses to $100 \mathrm{msec}$ test light steps $(700 \mathrm{~nm},-1.31)$. Backgrounds of $700 \mathrm{~nm},-4.89 ; 700 \mathrm{~nm},-3.95 ; 500 \mathrm{~nm},-8.14 ;$ and $500 \mathrm{~nm},-7.14$ were used in $A, B, C$, and $D$, respectively. The experiments were performed under dark-adapted condition, and the $\mathrm{HC}$ resting potential was $-20 \mathrm{mV}$.

(Hanani and Vallerga, 1980; Yang and Wu, 1989a). It is important to determine which population of the postsynaptic receptors in the HCs is modulatable by background illumination. Figure 11 shows the effect of background illumination on the spectral sensitivity of a dark-adapted HC. In darkness, the HC showed a spectral sensitivity which represented a mixture of rod and cone inputs (Wu and Yang, 1988; Yang and Wu, 1989a). In the presence of background illumination $(500 \mathrm{~nm} /-3.12)$ that induced large changes in HCRRT (represented by the large enhancement of the $\mathrm{HC}$ response to $100 \mathrm{msec}$ flashes; Fig. 2), the $\mathrm{HC}$ exhibited a spectral sensitivity that closely resembled that of the cones. This result suggests that the $\mathrm{HC}$ responses in the presence of background light is primarily mediated by cone inputs and the background-induced modulation of the HCRRT is probably acted mainly on the postsynaptic receptors to the cone transmitters.

Other evidence supporting this notion is given in Figure 12, which shows the effects of $700 \mathrm{~nm}$ background light on the $\mathrm{HC}$ responses to $500 \mathrm{~nm}$ test flashes. Similar to the results shown in Figures 2 and 3, where the wavelengths of the background and test lights were reversed, the $\mathrm{HC}$ responses to $100 \mathrm{msec}$ test flashes were enhanced by background illumination. However, the $\mathrm{HC}$ responses during the first $50 \mathrm{sec}$ after the termination of background light in Figure 12 were smaller than the responses before background was turned on. The HC responses after the termination of background light in Figures 2 and 3 were similar 


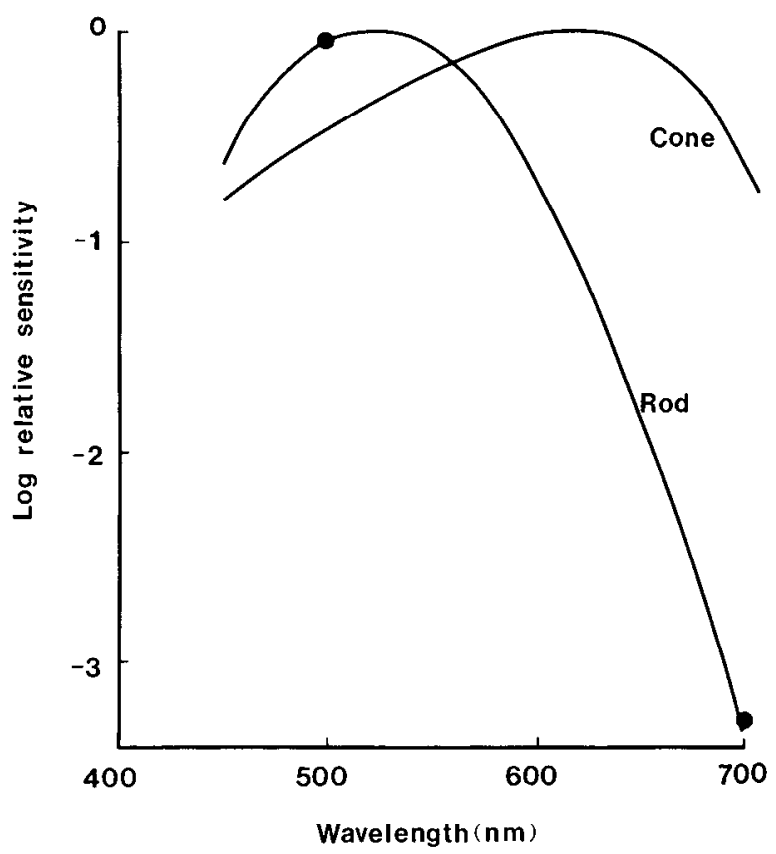

Figure 9. Spectral sensitivity of the change of HCRRT (solid circles) and the spectral sensitivity of the rod and the cone (solid lines). The solid circles were obtained by plotting the relative intensity of the background light of 2 wavelengths needed to produce a criterion degree of change in $\mathrm{HC}$ response amplitude to $100 \mathrm{msec}$ light steps.

to or larger than the responses before background light. Since the $\mathrm{HC}$ responses to $700 \mathrm{~nm}$ flashes consists of more cone input than those to $500 \mathrm{~nm}$ flashes, the greater reduction of response amplitude after background light, as shown in Figure 12, suggests that the background-induced changes in HCRRT (represented by the enhancement of responses to $100 \mathrm{msec}$ flashes) is probably mediated by events mainly associated with the cone inputs.

\section{Effects of pharmacological agents on the background-induced changes of the HCRRT}

Results described in previous sections have suggested that background probably modulates the cone inputs in dark-adapted $\mathrm{HCs}$ and the modulation depends on the rod voltage. It is of great interest to examine what pharmacological agents, especially the putative transmitters and compounds released from the photoreceptors and $\mathrm{HCs}$, affect this modulation. Therefore, we studied the effects of L-glutamate, L-aspartate, GABA, bicuculline, glycine, and strychnine on the $\mathrm{HC}$ responses. Moreover, various studies have demonstrated that cadaverine, putrescine, histidine, and melatonin are released from photoreceptors (Miller and Schwartz, 1983; Wiechmann, 1986) and that dopamine exerts modulatory action on HCs in the fish and turtle (Witkovsky and Stone, 1987; Yang et al., 1988b). We thus examined the effects of these compounds on the $\mathrm{HC}$ response time courses as well.

Table 1 summarizes the effects of the various pharmacological agents on the HCs in the dark-adapted tiger salamander retina. Some of these agents caused depolarization, some caused hyperpolarization, and some caused no change in the $\mathrm{HC}$ potential. None of these agents significantly affected the background-induced changes of the $\mathrm{HC}$ response rise time. The effect of GABA on the $\mathrm{HC}$ responses is given as an example in Figure 13. In normal Ringer's solution (Fig. 13A), background light expedited

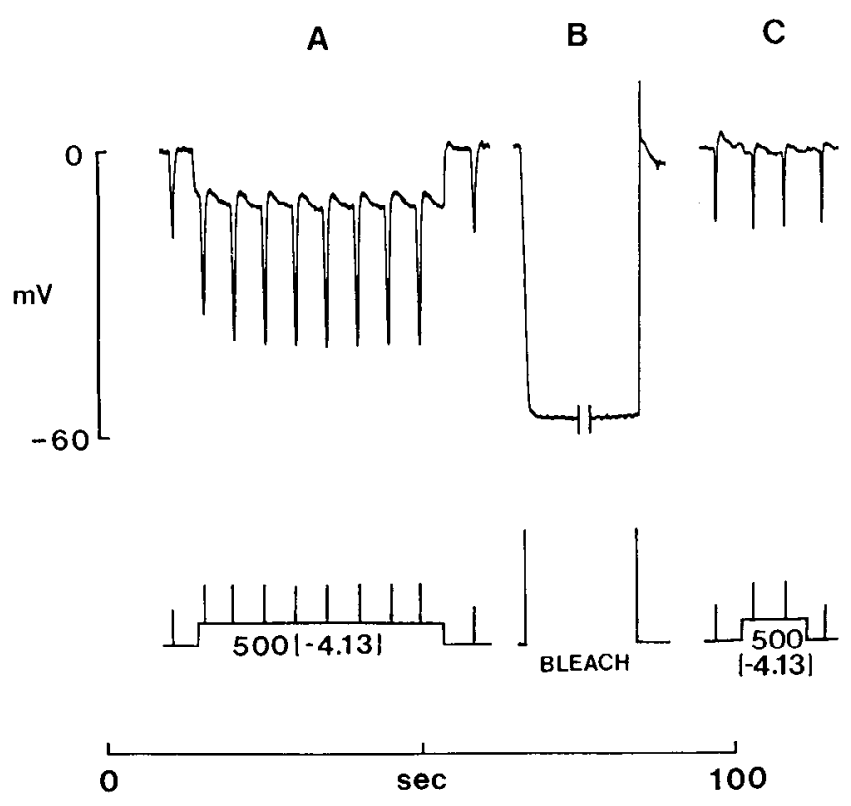

Figure 10. Effects of background illumination $(500 \mathrm{~nm} /-4.13)$ on the $\mathrm{HC}$ responses to $100 \mathrm{msec}$ light steps $(700 \mathrm{mn} /-1.31)$ before $(A)$ and after (C) bleaching. The bleaching light (white light, about $43 \mu \mathrm{W} / \mu \mathrm{m}^{2}$ ) was applied to the retina for about $1 \mathrm{~min}(B)$. The $\mathrm{HC}$ membrane potential returned to its dark-adapted level about $3 \mathrm{~min}$ after bleaching light was turned off $(C)$.

the $\mathrm{HC}$ rise time and the degree of this change, as represented by the ratio of the resultant response to the dark response, was 2.2. In the presence of $100 \mu \mathrm{M}$ GABA (Fig. 13B), the membrane potential of the $\mathrm{HC}$ did not change, but the response became slower and thus the response to $100 \mathrm{msec}$ flashes became smaller. Nevertheless, background light under this condition still ex-

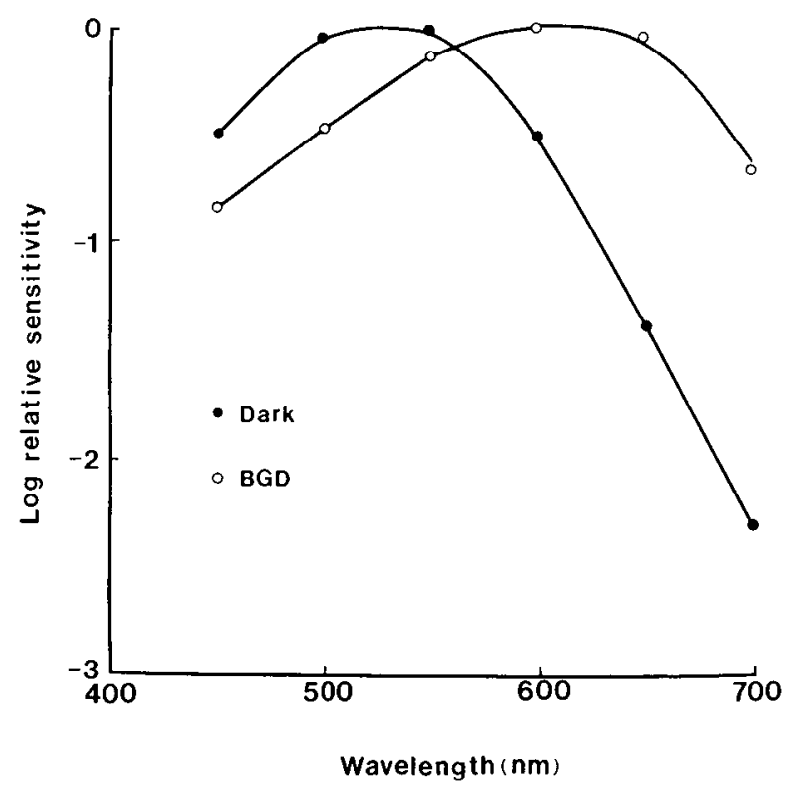

Figure 11. Effects of background illumination $(500 \mathrm{~nm},-3.12)$ on the spectral sensitivity of the dark-adapted HC. Filled circles represent the spectral sensitivity of the $\mathrm{HC}$ under dark-adapted condition and open circles represent the spectral sensitivity of the same cell in the presence of background illumination. The criterion voltage used to determine these spectral sensitivity curves was $2.5 \mathrm{mV}$. 
Figure 12. Effects of $700 \mathrm{~nm}$ background light $(-1.93)$ on the $\mathrm{HC}$ responses to $500 \mathrm{~nm}$ short $(100 \mathrm{msec})$ light steps $(-3.32)$. The $\mathrm{HC}$ was initially dark-adapted, and the resting potential was about $-21 \mathrm{mV}$.
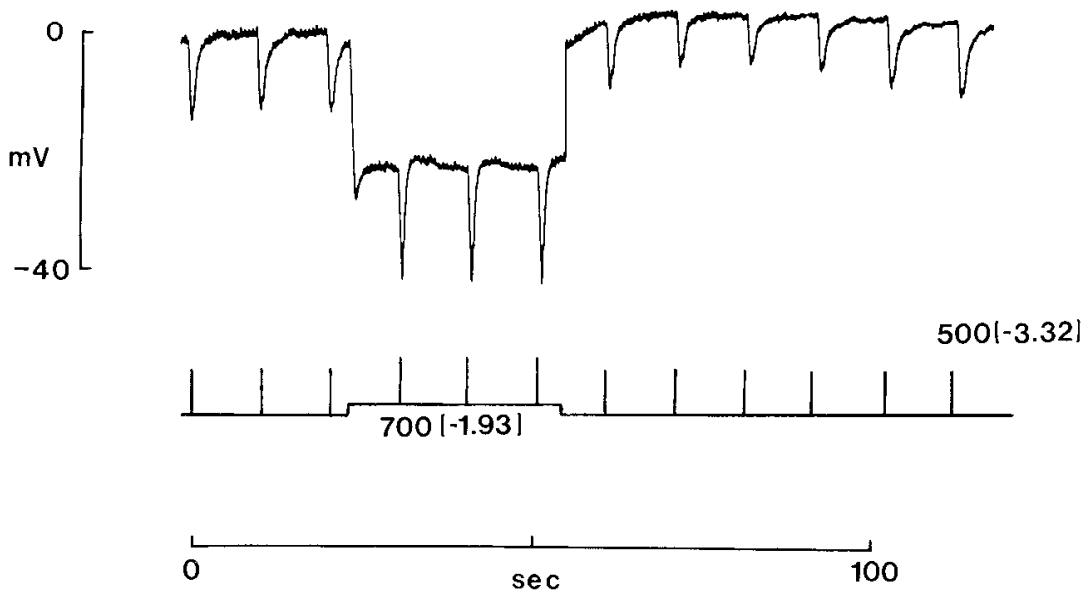

pedited the HCRRT and the degree of this change is even larger (3.0). This result demonstrates that although GABA can affect the time course of $\mathrm{HC}$ response (this will be discussed in a later paper, and also see Witkovsky and Stone, 1987), it does not significantly affect the background-induced changes of HCRRT in the tiger salamander retina.

\section{Effects of background illumination on the gain of the photoreceptor-HC synapses}

We have shown in the previous sections that background illumination expedites the HCRRT and enhances the responses to short test flashes. Figure $14 \mathrm{~A}$ shows the effect of background light on the $\mathrm{HC}$ responses to light steps of various durations. The ratio of the response amplitude in the presence of background to that in darkness (the relative gain) is plotted against

A

\section{Control}

$\mathrm{mV}{ }_{-40}^{0}$

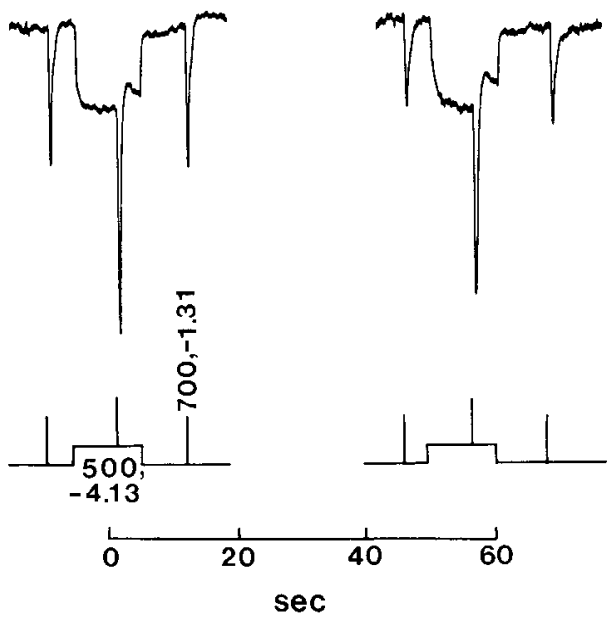

Figure 13. Effects of GABA on the background-induced changes of HCRRT. The same test light steps $(700 \mathrm{~nm},-1.31,100 \mathrm{msec})$ and background light $(500 \mathrm{~nm},-4.13,10 \mathrm{sec})$ were used to stimulate the IIC in normal Ringer's solution $(A)$ and in the presence of $100 \mu \mathrm{M}$ GABA $(B)$. GABA did not cause significant changes in the $\mathrm{HC}$ membrane potential, but it did slow the response rise time. GABA did not significantly affect the background-induced change in response time and amplitude. the light duration in Figure $14 B$. Both the increment and the resultant responses to short light steps were greatly enhanced by background illumination, but those to long light steps were not much affected. The cutoff duration $\left(T_{c}\right.$, defined as the longest duration of light step to which $\mathrm{HC}$ responses exhibit background-induced enhancement) for the $\mathrm{HC}$, shown in Figure 14, was about $600 \mathrm{msec} . T_{c}$ varied from $\mathrm{HC}$ to $\mathrm{HC}$ depending on the state of adaptation. The most dark-adapted $\mathrm{HC}$ exhibited a $T_{c}$ around $800 \mathrm{msec}$ and the partially light-adapted $\mathrm{HC}$ had $T_{c}$ around $200 \mathrm{msec}$. This result indicates that the backgroundinduced change in HCRRT can modify the relative gain of the photoreceptor-HC synapse, and the modification depends on the duration (or frequency) of the light stimuli.

Effects of background illumination on the response waveforms of the photoreceptors and second-order neurons

In the vertebrate retina, HCs exert inhibitory actions on cones and bipolar cells (Baylor et al., 1971; Naka, 1972; Toyoda and Tonosaki, 1978). Changes in $\mathrm{HC}$ responses lead to changes in responses of the cones and bipolar cells. Figure 15 shows the effects of background light on the response waveforms of the dark-adapted photoreceptors and second-order neurons in the tiger salamander retina. Figure $15 \mathrm{~A}$ shows the voltage responses of a rod, a cone, a $\mathrm{HC}$, a $\mathrm{DBC}$, and a $\mathrm{HBC}$ to a $1 \mathrm{sec}$ light step under dark-adapted condition; Figure $15 B$ shows the voltage

Table 1. Effects of pharmacological agents on HCs

\begin{tabular}{lll} 
& HC membrane & $\begin{array}{l}\text { Background- } \\
\text { induced } \\
\text { change in HC } \\
\text { response }\end{array}$ \\
\hline Test substance & $\begin{array}{l}\text { dep. } \\
\text { potential }\end{array}$ & None \\
L-Glutamate $(0.1-2 \mathrm{~mm})$ & No change & None \\
L-Aspartate $(0.1-2 \mathrm{~mm})$ & No change & None \\
GABA $(0.1-1 \mathrm{mM})$ & No change & None \\
Bicuculline $(0.05-1 \mathrm{~mm})$ & No change & None \\
Glycine $(0.01-10 \mathrm{~mm})$ & dep. & None \\
Strychnine $(0.05-1 \mathrm{~mm})$ & No change & None \\
Cadaverine $(0.1-1 \mathrm{~mm})$ & hyp. & None \\
Putresine $(0.1-1 \mathrm{~mm})$ & hyp. & None \\
$N$-Acetylhistidine $(0.1-1 \mathrm{mM})$ & hyp. & None \\
Melatonin $(0.1-1 \mathrm{~mm})$ & &
\end{tabular}


A
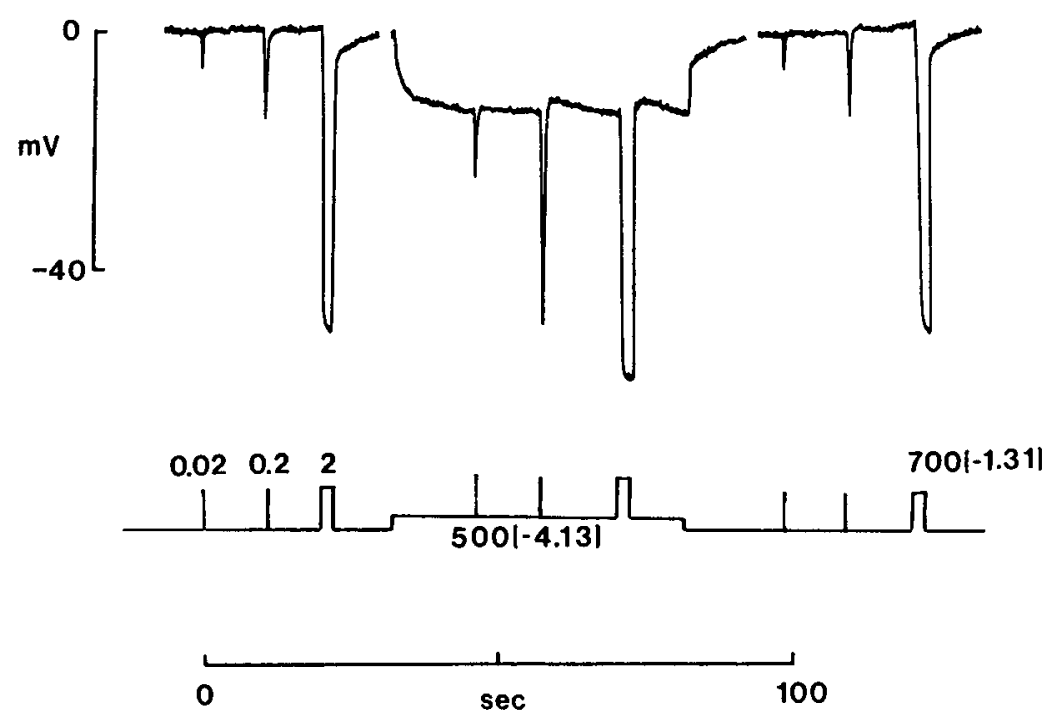

B

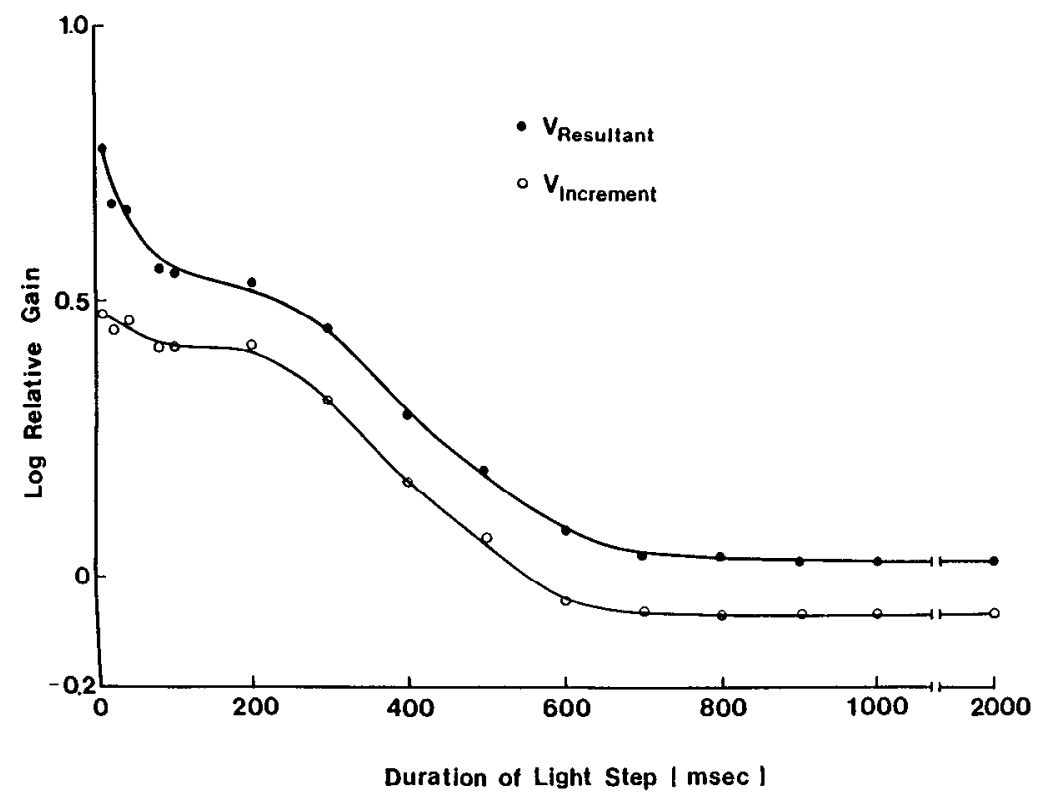

Figure 14. Effects of background illumination on the $\mathrm{HC}$ responses to light steps of various durations. $A, \mathrm{HC}$ responses to light steps $0.02,0.2$, and 2 $\sec (700 \mathrm{~nm}, 1.31)$ in duration in the absence and presence of background illumination $(500 \mathrm{~nm},-4.13)$. $B$, Relations of the relative gain (HC responses with background/HC responses without background, in $\log$ scale) and the duration of the light steps. Open circles give the relative gain of the increment responses, and filled circles give that of the resultant responses (increment responses + background responses).

responses of these cells to the same light steps in the presence of background illumination. Note that the $\mathrm{HC}$ response in Figure $15 B$ was much larger than that in $A$ because its rising phase was faster. The responses of the cone and bipolar cells in the 2 panels exhibited approximately the same amplitude but different waveforms. The responses are more transient (arrows) in Figure $15 B$ than in $A$. It is possible that part of these transient responses in $B$ is attributable to the faster and larger $\mathrm{HC}$ response which sags the cone and bipolar cell responses at a faster rate through inhibitory synapses (Baylor et al., 1971; Toyoda and Tonosaki, 1978; Attwell et al., 1983).

\section{Discussion}

\section{Background-induced change of the HCRRT}

In this paper, we have demonstrated that background illumination expedites the rise time course of the HC light response, and this change in response time course is more then 10 times the change in rise time occurring in cones and bipolar cells. The change correlates very well with the changes in rod voltage but not with changes in $\mathrm{HC}$ voltage. We postulate that the postsynaptic receptors to cone transmitters in the $\mathrm{HC}$ membrane are the modulation sites. This is reasonable because our experiments demonstrated that the background-induced modulation does not occur in photoreceptors or bipolar cells. The response rise times of these cells are much faster than that of the horizontal cclls under dark-adaptcd condition, and thcy cxhibit littlc change in response to background illumination (Fig. 15). Bipolar cells share the same photoreceptor synapses with the $\mathrm{HC}$ in this retina (Lasansky, 1973, 1978), and hence the absence of modulation in bipolar cells eliminates the presynaptic terminals and synaptic clefts as the modulation sites. Our experiments show that the HCRRT is independent of the HC voltage, and thus voltage-dependent ionic currents in the $\mathrm{HC}$ membrane are unlikely to limit the $\mathrm{HC}$ response rise time. This conclusion is 
Figure 15. Voltage responses of a rod, a cone, a HC, a DBC, and a HBC under dark-adapted condition $(A)$ and in the presence of background illumination $(B)$. The test step used in both $A$ and $B$ was $700 \mathrm{~nm},-1.35$ and the background in $B$ was $520 \mathrm{~nm},-4.06$. Note that the $\mathrm{HC}$ response to the $1 \mathrm{sec}$ light step is larger in $B$, and the cone and bipolar cell responses are more transient (arrows) in $B$.
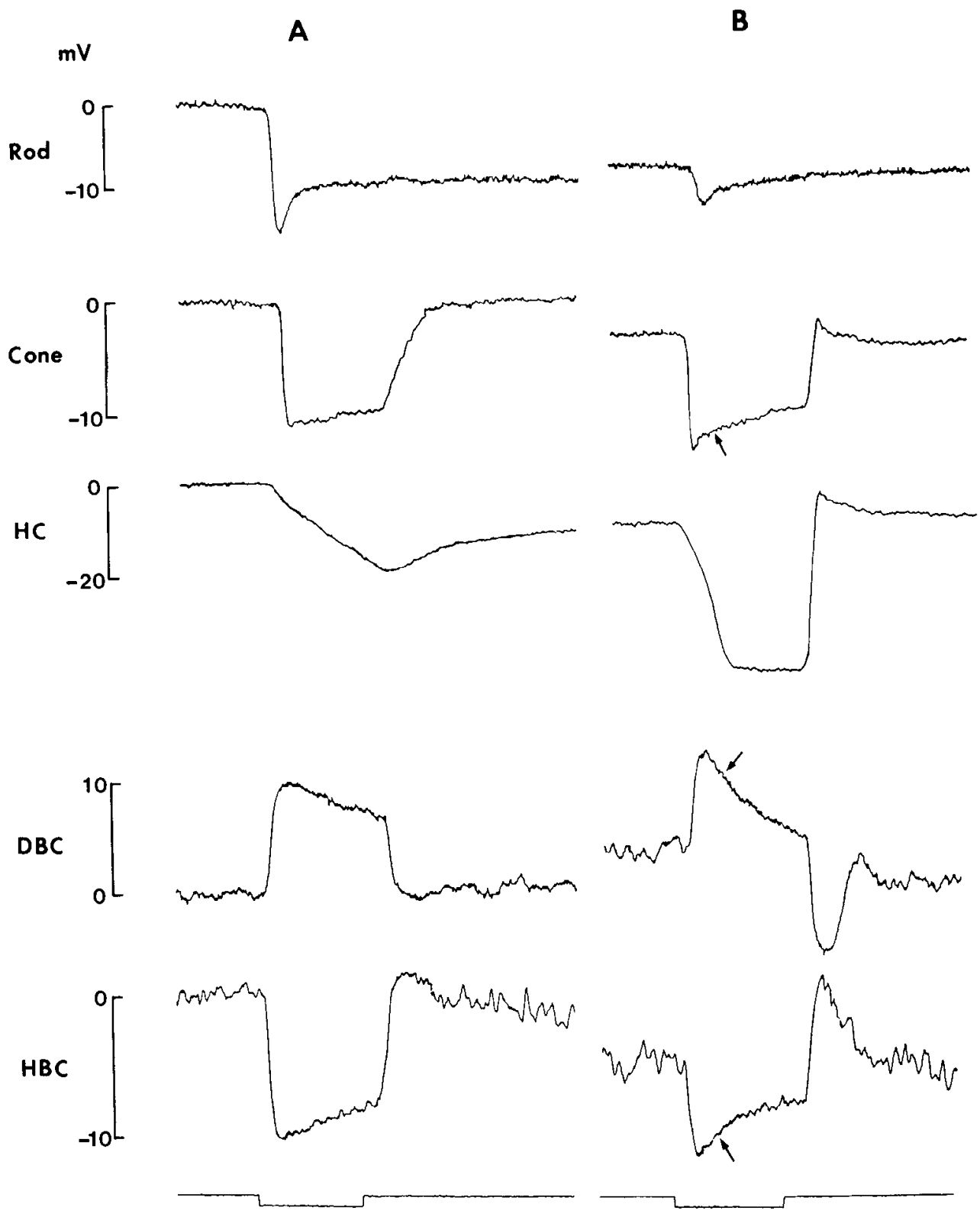

consistent with our previous study showing that the HCRRT under dark-adapted condition is much slower than that under light-adapted condition at the same resting potential $(\mathrm{Wu}, 1987 \mathrm{~b}$, figure 2). We have shown in this article that background light modulates the efficacy and kinetics of the transmitter-receptor complexes in the HCs. In the fish retina; it has been shown that dopamine, whose concentration is controlled by light, regulates the transmitter-gated conductances in the $\mathrm{HC}$ membrane (Knapp and Dowling, 1987). Similar mechanisms may be responsible for the background-induced change in the $\mathrm{HC}$ response time in the tiger salamander retina.

In the vertebrate retina, the electrotonic coupling between HCs is modulatable by dopamine and possibly other agents (Lasater and Dowling, 1985; Witkovsky et al., 1987; Tornqvist et al., 1988). However, HC coupling is unlikely to play a significant role in mediating the background-induced change in the $\mathrm{HC}$ responses. In our experiments, we used whole-field illumination, which results in no net lateral current flowing across electrical synapses between HCs. Based on the dimensions of the $\mathrm{HC}$ dendrites and somas in the tiger salamander retina (Lasansky, 1973), the cable characteristics of HCs are unlikely to be responsible for a time course difference on the order of seconds as we described in this article (Jack et al., 1975). Moreover, dopamine and related agents caused no significant change in the $\mathrm{HC}$ response time course.

Another factor that may affect the HCRRT is the light-dependent change of potassium concentration in the extracellular space $\left[K_{o}\right]$ (Oakley et al., 1979). Instead of the dissociation of 
the transmitter-receptors complexes in the $\mathrm{HC}$ membrane, the rate-limiting factor of the rise of the $\mathrm{HC}$ light responses may be limited by the downward drift of the potassium equilibrium potential $\left(E_{\mathrm{K}}\right)$ in response to lowering $\left[\mathrm{K}_{0}\right]$. However, assuming all neurons in the outer retina have similar permeability to $\mathrm{K}^{+}$, this factor is unlikely to be significant in mediating the HCRRT. This is because bipolar cells, whose dendrites and somas are adjacent to the HCs, do not exhibit either the slow response rise time in darkness or the background-induced change in their responses.

In the retina, horizontal cells make inhibitory feedback synapses onto cones (Baylor et al., 1971), and modification of this negative-feedback synapse may result in changes in the kinetics and gain of the forward synapses from photoreceptors to secondorder cells (Marmarelis and Naka, 1973). In the fish and tiger salamander retinas, GABA is believed to be the primary neurotransmitter used by the HCs in the feedback synapse (Lam and Steinman, 1971; Tachibana and Kaneko, 1984; Wu, 1986). Our experiments show that neither GABA nor bicuculline blocks the background-induced changes in HCRRT (Fig. 11, Table 1). These results suggest that if GABA is the feedback transmitter used by the HCs in the tiger salamander retina, then the feedback synapses probably play little role in mediating the backgroundinduced changes of the HCRRT.

Our failure in identifying the blocking agent for the background-induced change of the HCRRT prevents us from suggesting what modulator(s) is (are) involved in modulating the inactivation of the transmitter-receptor complexes in the cone$\mathrm{HC}$ synapse. None of the substances listed in Table 1 significantly affected the background-induced changes of the HCRRT, although some of these substances altered the membrane potential and/or the response amplitude of the HCs. Although the identity of the modulator involved is unknown, our experiments provide important clues on the mechanisms of the backgroundinduced modulation. Figure 3 and 4 show that the time course of inactivation of the modulators induced by background illumination is only about $2 \mathrm{sec}$. This short time course implies that complex biochemical processes may not be involved in the background-induced modulation of the cone-HC synapse. In a later article, we will present data showing that a long-term (time course, 5-10 $\mathrm{min}$ ) modulation of the photoreceptor-HC synapse also exists in the tiger salamander retina (Yang and $\mathrm{Wu}, 1989 \mathrm{~b}$ ).

\section{Rod-cone interaction in the tiger salamander retina}

Recent psychophysical studies have described a suppressive rodcone interaction, and it is attributed to a tonic, inhibitory influence of dark-adapted rods on cone-mediated pathways (Alexander and Fishman, 1984; Arden and Frumkes, 1986). Physiologically, Hassin and Witkovsky (1983) have demonstrated that rod-stimulating lights enhance the cone-mediated $\mathrm{HC}$ responses in the Xenopus retina, and Frumkes and Eysteinsson (1987) have shown that backgrounds enhance the peak-to-peak amplitude of the responses to sinusoidal flickers in cones, HCs, and bipolar cells of the mudpuppy and Xenopus. Our results in the tiger salamander retina support the notion that backgrounds modulate the cone-mediated $\mathrm{HC}$ responses through modulators associated with the rods. However, we have shown that the mechanisms of the suppressive rod-cone interaction in the tiger salamander retina differ from those in the Xenopus and mudpuppy in at least 2 respects: (1) We have shown that the background-induced modulation of the cone-mediated response is primarily observed in HCs but not in cones or bipolar cells, and
(2) the background-induced modulation of the cone-HC synapse is primarily in the time domain. Background lights expedite the HCRRT for about $0.5-1 \mathrm{sec}$ but do not affect the peak amplitude of the $\mathrm{HC}$ response significantly. These differences between our results and those described by Hassin and Witkovsky, and Frumkes and Eysteinsson, may be due to species differences. It is worth noticing that background illumination also expedites the response rise time in cones and bipolar cells in the tiger salamander retina (Fig. 15), but this change is no more than 50 msec, and thus the amplitudes of the cone and bipolar cell responses to $100 \mathrm{msec}$ test flashes are affected little.

\section{Functional implications of the response rise time in neurons in the outer retina}

In the tiger salamander retina, we have shown that the response rise time of the $\mathrm{HCs}$ is much slower than that of the photoreceptors or bipolar cells and that background illumination expedites the $\mathrm{HC}$ response much more than expediting the photoreceptors or bipolar cell responses. These results suggest that the photoreceptor-bipolar cell (R-BC) synapse and the photoreceptor-horizontal cell ( $\mathrm{R}-\mathrm{HC}$ ) synapse have different frequency responses, and the $\mathrm{R}-\mathrm{HC}$ synapse is more plastic, with a frequency response modulatable by light (Fig. 14). Bipolar cells are the output neurons of the outer retina, and they receive central input from the photoreceptors and antagonistic lateral input from $\mathrm{HCs}$ whose responses are mediated by the R-HC synapse. The difference in frequency response and plasticity between the R-BC and R-HC synapses have several consequences in bipolar cell signaling.

In the time domain, the $\mathrm{HC}$ responses mediate a delayed signinventing signal in bipolar cells and make the bipolar cell response more transient (Werblin, 1977). The delay between the $\mathrm{HC}$ signal and the photoreceptor signal in bipolar cells is partially mediated by the delay of signal passing through the $\mathrm{HC}$ $\mathrm{BC}$ synapse and partially by the difference in response rise time between the HCs and bipolar cells. Our results in this article show that background illumination expedites the HCRRT and thus it shortens the delay between the $\mathrm{HC}$ input and the photoreceptor input in bipolar cells. This makes the bipolar cell responses more transient in the presence of background illumination (Fig. 15). Even in the presence of background, the time-to-peak of the HC responses is still about 200 msec longer than that of the bipolar cell responses. Consequently, the amplitude of bipolar cell peak responses (or responses to short light steps) is not significantly affected by background illumination (Fig. 15). The amplitude of the bipolar cell plateau responses, on the other hand, is reduced in a faster rate with background light than in darkness, because the $\mathrm{HC}$ responses reach their peaks at a faster rate. In other words, the bipolar cell responses to short (or high-frequency) light stimuli can be transmitted to the inner retina with little inhibition from the HCs. The amplitudes of bipolar cell responses to long (or low-frequency) light stimuli are reduced by the $\mathrm{HC}$ inhibitory signal whose time course is adjustable by background illumination: background speeds up the HC signal and makes the inhibition stronger for shorter (or higher-frequency) light stimuli. Based on this view, the $\mathrm{HC}$ responses are probably involved in reducing the sustained (or low-frequency) signals in bipolar cells. It is probably economical, if not advantageous, for the retina to transmit only information on the changes of images, than to constantly transmit the same information on the unchanged image (Srinivasan et al., 1982; Attwell, 1986). In the presence of background light, 
the need for reducing sustained information is probably even more critical than under dark-adapted condition because background light sets up a sustained signal level itself and changes of signals about this sustained level become more important (Srinivasan et al., 1982).

In the spatial domain, $\mathrm{HC}$ responses give rise to the antagonistic surround responses in cones and bipolar cells (Werblin and Dowling, 1969; Baylor et al., 1971; Naka, 1972). The spatial frequency sensitivity of bipolar cells to visual images can be obtained as the Fourier transform of the center-surround receptive field of the cells (Campbell and Robson, 1968). Horizontal cells average the light intensity over a much larger area than do the bipolar cell dendrites and this results in a fall of the bipolar cell spatial frequency sensitivity curve at low frequencies (Attwell and Wilson, 1983). Because of the slow rise time and the modulability of the $\mathrm{HC}$ responses, the antagonistic surround responses and the spatial frequency sensitivity of the bipolar cells becomes duration (or temporal frequency) dependent. For short (or high temporal frequency) light stimuli, the surround responses in bipolar cells are small, which may be partially responsible for the disappearance of the surround responses of retinal ganglion cells following prolonged dark adaptation (Barlow et al., 1957). The spatial frequency sensitivity of bipolar cells does not fall off significantly at low frequencies, resulting in a lower sensitivity to edges in the visual image (Attwell and Wilson, 1983). For long (or low temporal frequency) light stimuli, the bipolar cell surround responses are larger and the spatial frequency sensitivity of bipolar cells falls off sharply at low frequencies, resulting in a higher sensitivity to edges in the visual image. Background illumination expedites the $\mathrm{HC}$ rise time and thercfore pushes the capability for higher spatial resolution to a lower temporal level (shorter stimulus duration, higher stimulus frequency) in bipolar cells.

\section{References}

Alexander, K. R., and G. A. Fishman (1984) Rod-cone interaction in flicker perimetry. Br. J. Ophthalmol. 68: 303-309.

Arden, G. B., and T. E. Frumkes (1986) Stimulation of rods can increase cone flicker ERGs in man. Visual Res. 26: 711-721.

Attwell, D. (1986) Ion channels and signal processing in the outer retina. Q. J. Exp. Physiol. 71: 497-536.

Attwell, D., and M. Wilson (1983) The spatial frequency sensitivity of bipolar cells. Biol. Cybern. 47: 131-140.

Attwell, D., F. S. Werblin, M. Wilson, and S. M. Wu (1983) A signreversing pathway from rods to double and single cones in the retina of the tiger salamander. J. Physiol. (Lond.) 336: 313-333.

Barlow, H. B., R. Fitzhugh, and S. W. Kuffler (1957) Change of organization in the receptive field of the cat's retina during dark adaptation. J. Physiol. (Lond.) 137: 338-354.

Baylor, D. A., and A. L. Hodgkin (1974) Changes in the time scale and sensitivity in the turtle photoreceptors. J. Physiol. (Lond.) 242: 729-758.

Baylor, D. A., M. G. F. Fuortes, and P. M. O'Bryan (1971) Receptive fields of single cones in the retina of the turtle. J. Physiol. (Lond.) 24: 265-294.

Byzov, A. L., and J. A. Trifonov (1968) The response to electric stimulation of horizontal cell in the carp retina. Vision Res. 8: 817822.

Campbell, F. W., and J. G. Robson (1968) Application of Fourier analysis to the visibility of granting. J. Physiol. (Lond.) $371: 36 \mathrm{P}$.

Dacheux, F. F., and R. F. Miller (1976) Photoreceptor-bipolar cell transmission in the perfused retina eyecup of the mudpuppy. Science 191: 963-964.

Dowling, J. E., and H. Ripps (1973) Effects on magnesium on horizontal cell activity in the skate retina. Nature 242: 101-103.
Frumkes, T. E., and T. Eysteinsson (1987) Suppressive rod-cone interaction in distal vertebrate retina: Intracellular records from xenopus and necturus. J. Neurophysiol. 57: 1361-1382.

Hanani, M., and S. Vallerga (1980) Rod and cone signals in the horizontal cells of the tiger salamander retina. J. Physiol. (Lond.) 298: 397-405.

Hassin, G., and P. Witkovsky (1983) Intracellular recording from identified photoreceptors and horizonal cells of the xenopus retina. Vision Res. 23: 921-932.

Knapp, A . G., and J. E. Dowling (1987) Dopamine enhances excitatory amino-acid-gated conductances in cultured retinal horizontal cells. Nature $325: 437-439$.

Lam, D. M. K., and L. Steinman (1971) The uptake of 3H-GABA in the goldfish retina. Proc. Natl. Acad. Sci. USA 68: 2777-2781.

Lasansky, A. (1973) Organization of the outer synaptic layer in the retina of the larval tiger salamander. Phil. Trans. R. Soc. B 265:471489.

Lasansky, A. (1978) Contacts between receptors and electro-physiological identified neurons in the retina of the larval tiger salamander. J. Physiol. (Lond.) 285: 531-542.

Lasater, E. M., and J. E. Dowling (1985) Dopamine decreases conductance of the electrical junction between cultured retinal horizontal cells. Proc. Natl. Acad. Sci. USA 82: 3025-3029.

Marmarelis, Pl. Z., and K. I. Naka (1973) Non-linear analysis and synthesis of receptive-field responses in the catfish retina. I. Horizontal to ganglion cell chain. J. Neurophysiol. 36: 605-718.

Miller, A. M., and E. A. Schwartz (1983) Evidence for the identification of synaptic transmitters released by photoreceptors of the toad retina. J. Physiol. (Lond.) 334: 325-350.

Naka, K. I. (1972) The horizontal cell. Vision Res. 12: 573-588.

Oakley, B. I., D. G. Flaming, and K. T. Brown (1979) Effects of the rod receptor potential upon retinal extracellular potassium concentration. J. Gen. Physiol. 74: 713-737.

Schacher, S., E. Holtzman, and D. Hood (1974) Uptake of horseradish peroxidase by frog photoreceptor synapses in the dark and light. $\mathrm{Na}$ ture 249: 261-263.

Srinivasan, M. V., S. B. Laughlin, and A. Dubs (1982) Predictive coding: A fresh view of inhibition in the retina. Proc. R. Soc. London [Biol.] 216: 472-479.

Tachibana, M. (1983) Ionic currents of solitary horizontal cell isolated from goldfish retina. J. Physiol. (Lond.) 345: 329-351.

Tachibana, M., and A. Kaneko (1984) $\gamma$-aminobutyric acid acts at axon terminals of turtle photoreceptors: Difference in sensitivity among cell types. Proc. Natl. Acad. Sci. USA 81: 7961-7964.

Tauchi, M., X. L. Yang, and A. Kaneko (1984) Depolarizing responses of L-type external horizontal cells in the goldfish retina under intense chromatic background. Vision Res. 24: 867-870.

Tornqvist, K., X. L. Yang, and J. E. Dowling (1988) Modulation of cone horizontal cell activity in the teleost fish retina. III. Effects of prolonged darkness and dopamine on electrical coupling between horizontal cells. J. Neurosci. 8: 2279-2288.

Toyoda, J.-I., and K. Tonosaki (1978) Effect of polarization of horizontal cells on the on-center bipolar cells of the carp retina. Nature 276: 399-400.

Werblin, F. S. (1977) Synaptic mechanisms mediating bipolar response in the retina of the tiger salamander. In Vertebrate Photoreception. H. B. Barlow and P. Fatt, eds., pp. 205-230, Academic, New York.

Werblin, F. S. (1978) Transmission along and between rod in the tiger salamander retina. J. Physiol. (Lond.) 280: 449-470.

Werblin, F. S., and J. E. Dowling (1969) Organization of the retina of the mudpuppy, Necturus Maculosus. II. Intra-cellular recording. J. Physiol. (Lond.) 32: 339-355.

Wiechmann, A. F. (1986) Melatonin: Parallels in pineal gland and retina. Exp. Eye Res. 42:-407-527.

Witkovsky, P., and S. Stone (1987) GABA and glycine modify the balance of rod and cone inputs to horizontal cells in the xenopus retina. Exp. Biol. 47: 13-22.

Witkovsky, P., S. Stone, and J. Besharse (1987) Dopamine mimics light-adaption in horizontal cells of the xenopus retina. Soc. Neurosci. Abstr. 12: 24.

Wu, S . M. (1986) Effects of gamma-aminobutyric acid on cones and bipolar cells of the tiger salamander retina. Brain Res. 365: 70-77.

Wu, S. M. (1987a) Changes in response waveform of retinal horizontal cells during dark and light adaptation. Vision Res. 27: 143-150. 
Wu, S. M. (1987b) Light-dependent synaptic delay between photoreceptors and horizontal cells in the tiger salamander retina. Vision Res. 27: 363-367.

Wu, S. M. (1987c) Synaptic connections among retinal neurons in living slices. J. Neurosci. Methods 20: 139-149.

Wu, S. M. (1988) The depolarizing off-responses of photoreceptors and horizontal cells in light-adapted retinas of the larval tiger salamander. Exp. Eye Res. 47: 261-268.

Wu, S. M., and X. L. Yang (1988) Electrical coupling between rods and cones in the tiger salamander retina. Proc. Natl. Acad. Sci. USA 85: 275-278.

Yang, X. L., and S. M. Wu (1989a) Synaptic inputs from rods and cones to horizontal cells in the tiger salamander retina. Sci. Sin. (in press).
Yang, X. L., and S. M. Wu (1989b) Effects of prolonged light cxposurc, gamma-aminobutyric acid and glycine on the horizontal cell responses in the tiger salamander retina. J. Neurophysiol. (in press).

Yang, X. L., K. Tornqvist, and J. E. Dowling (1988a) Modulation of cone horizontal cell activity in the teleost fish retina. I. Effects of prolonged darkness and background illumination on light responsiveness. J. Neurosci. 8: 2259-2268.

Yang, X. L., K. Tornqvist, and J. E. Dowling (1988b) Modulation of cone horizontal cell activity in the teleost fish retina. II. Role of interplexiform cells and dopamine in regulating light responsiveness. J. Neurosci. 8: 2269-2278. 